\title{
Lipid profile in psoriasis patients
}

\section{Ramesh Marne Bhat Hyacinth Peter Pinto}

Department of Dermatology, Fr Muller Medical College, Kankanady, Mangalore, India

\section{Video abstract}

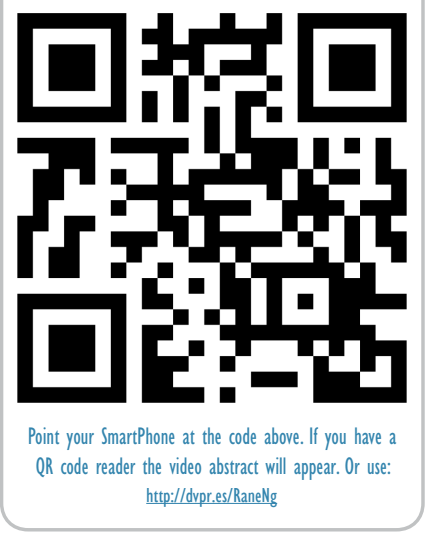

Correspondence: Ramesh Marne Bhat Dept of Dermatology, Fr Muller Medical College, Kankanady, Mangalore-575002, India

Email rameshderma@yahoo.com
This article was published in the following Dove Press journal:

Psoriasis: Targets and Therapy

8 November 2012

Number of times this article has been viewed

Objective: To compare the lipid profile values of psoriatic patients with those of age and sexmatched nonpsoriatic controls, while providing a review of the literature.

Methods: A total of 20 consecutive patients with chronic plaque psoriasis ( 18 males and two females) and 20 age- and sex-matched healthy individuals without psoriasis were included as controls in this study. Serum levels of cholesterol, triglycerides, low-density lipoprotein, and high-density lipoprotein were measured after 12 hours of overnight fasting.

Results: The serum levels of total and low-density lipoprotein cholesterol were found to be higher in both the psoriatic and the control group; thus there were no statistically significant difference between both groups of individuals.

Conclusion: Psoriasis is now emerging as an important systemic disease associated with various comorbid conditions that include diabetes, hypertension, and an abnormal lipid profile as reviewed by various studies. Such comorbid conditions that are linked with psoriasis have been associated with increasing rates of morbidity and mortality. Our study indicated that there was an increase in total and low-density lipoprotein cholesterol in both patients and controls, indicating that there is an overall increase of these levels in the general population. Therefore, it is important that the lipid profiles of these patients continue to be studied.

Keywords: psoriasis, lipid profile, serum cholesterol, serum triglycerides, serum LDL, serum HDL

\section{Introduction}

Psoriasis is a common, chronic, inflammatory, and proliferative skin disease associated with abnormal lipid metabolism. Its prevalence in the population is affected by genetic, environmental, viral, infectious, immunological, biochemical, hormonal, and psychological factors, as well as by alcohol and drug abuse. ${ }^{1}$

Lipid abnormalities are detectable in psoriasis patients at the earliest stages of the disease and may therefore be genetically determined. ${ }^{2}$ Previous studies have demonstrated that patients with psoriasis may have an increased risk of a variety of noncutaneous diseases, including arterial and venous occlusive diseases. Changes in the plasma lipid and lipoprotein composition in patients with psoriasis may be the reason for the increased risk of atherosclerosis in these individuals. ${ }^{3,4}$ In addition to the immunological similarities found in association with different psoriasis-related comorbidities, there are likely genes that are common to psoriasis and other complex disorders, including HLA-Cw6 and tumor necrosis factor-alpha (TNF-alpha). ${ }^{1}$

In recent years, psoriasis has been recognized as a systemic disease associated with numerous multiorgan abnormalities and complications. ${ }^{1}$ In psoriatic 
patients, an increased risk of cardiovascular abnormalities, hypertension, dyslipidemia, atherosclerosis, diabetes mellitus type two, obesity, chronic obstructive pulmonary disease, cerebral stroke, osteoporosis, cancer, and depression have been found. The existing literature also suggests that lipid metabolism disorders may play a role in psoriasis pathogenesis; ${ }^{1,2}$ hence there is a great need to study lipid abnormalities in psoriatic patients, which will help us evaluate the level of risk individuals may experience for developing atherosclerosis and vascular obstructive disorders, as well as associated morbidity and mortality.,6

In the current study, we measured the serum total cholesterol, triglyceride, high density lipoprotein (HDL), and low density lipoprotein (LDL) levels in patients with psoriasis and compared these levels with those from healthy controls.

\section{Patients and methods}

A total of 20 consecutive patients (18 males and two females) with moderate to severe chronic plaque psoriasis (presenting with a Psoriasis Area Severity Index of more than 10) were enrolled in this study. Patients with erythrodermic and guttate psoriasis were excluded. A similar number of healthy, ageand sex-matched individuals without psoriasis were included as controls. Patients with diseases that can cause secondary hyperlipidemia (eg, hypothyroidism, diabetes mellitus, nephrotic syndrome, etc) and patients who were currently taking or had taken medications such as antihypertensives, corticosteroids, and lipid lowering agents within 6 months of the study period were excluded. The estimation of these levels was done across both groups after 12 hours of overnight fasting.

The Student's $t$-test was applied to compare the means among the different parameters at a $95 \%$ confidence interval.

\section{Results}

The results of this study are shown in Table 1 . A total of 40 participants (20 psoriatic patients and 20 controls) with a mean age of 48 years (ranging between 36-65 years) were enrolled in this study. Total cholesterol levels were elevated in nine patients and 12 controls. The serum triglyceride levels were elevated in two patients and eight controls. The serum HDL level was lower in ten patients and six controls. The serum LDL levels were elevated in 16 patients and ten controls. A $P$-value of $<0.05$ was considered to be significant. Each of these parameters was similar between patients and controls, and the comparison was not statistically significant.

\section{Discussion}

Lipid metabolism studies among individuals with psoriasis have been conducted since the beginning of the 20th century, and many have concentrated on skin surface lipids, stratum corneum lipids, epidermal phospholipids, serum lipids, dermal LDL in the psoriatic skin, lipid metabolism, and oxidative stress, as well as correlations between inflammatory parameters and lipid parameters with the clinical symptoms of the disease. The data from the current literature on psoriasis suggests that an association between lipid and immunologic abnormalities has been observed, and that

Table I Patient serum total cholesterol, serum triglyceride, serum high-density lipoprotein, and serum low-density lipoprotein levels

\begin{tabular}{|c|c|c|c|c|c|c|c|}
\hline & \multirow[t]{2}{*}{$\mathbf{n}$} & \multirow[t]{2}{*}{ Mean } & \multirow{2}{*}{$\begin{array}{l}\text { Standard } \\
\text { deviation }\end{array}$} & \multicolumn{2}{|c|}{$95 \%$ confidence interval for mean } & \multirow[t]{2}{*}{$t$-value } & \multirow[t]{2}{*}{$P$-value } \\
\hline & & & & Lower bound & Upper bound & & \\
\hline \multicolumn{8}{|c|}{ Serum total cholesterol } \\
\hline Cases & 20 & 204.85 & 43.313 & 184.58 & 225.12 & 0.025 & 0.980 \\
\hline Controls & 20 & 205.20 & 44.452 & 184.40 & 226.00 & & NS \\
\hline Total & 40 & 205.03 & 43.320 & 191.17 & 218.88 & & \\
\hline \multicolumn{8}{|c|}{ Serum triglyceride } \\
\hline Cases & 20 & 94.55 & 40.875 & 75.42 & 113.68 & 3.901 & 0.000 \\
\hline Controls & 20 & 174.10 & 81.536 & 135.94 & 212.26 & & HS \\
\hline Total & 40 & 134.33 & 75.335 & 110.23 & 158.42 & & \\
\hline \multicolumn{8}{|c|}{ Serum high-density lipoprotein } \\
\hline Cases & 20 & 42.65 & 10.540 & 37.72 & 47.58 & 0.029 & 0.977 \\
\hline Controls & 20 & 42.55 & 11.157 & 37.33 & 47.77 & & NS \\
\hline Total & 40 & 42.60 & 10.713 & 39.17 & 46.03 & & \\
\hline \multicolumn{8}{|c|}{ Serum low-density lipoprotein } \\
\hline Cases & 20 & 146.40 & 39.723 & $|27.8|$ & 164.99 & 0.024 & 0.981 \\
\hline Controls & 20 & 146.10 & 39.284 & $|27.7|$ & 164.49 & & NS \\
\hline Total & 40 & 146.25 & 38.995 & 133.78 & 158.72 & & \\
\hline
\end{tabular}

Abbreviations: NS, not significant; HS, highly significant. 
for this reason this disease could also be described as an immunometabolic syndrome. ${ }^{1}$

Almost half a century ago, Lea et $\mathrm{al}^{7}$ reported increased serum lipid concentrations in patients with psoriasis. Recent advances in the understanding of the role of inflammatory cells in the pathogenesis of psoriasis has shifted the clinical perspective on psoriasis from that of a skin disorder to that of a systemic inflammatory process, which may increase the prevalence of other comorbid conditions in this patient population. Similar to psoriasis, metabolic syndrome (which includes central obesity, hypertension, type two diabetes mellitus, hypertriglyceridemia, and low HDL cholesterol levels) is characterized by an increase in the immunological activity of type one helper T cells, suggesting that psoriasis may be associated with metabolic syndrome because of shared inflammatory pathways. ${ }^{1}$

Psoriasis is a chronic inflammatory condition characterized by increased $\mathrm{T}$ helper-1 and T helper-17 cell activity. ${ }^{1}$ In addition to the immunological similarities of psoriasis and its related comorbidities, there are likely several other genes that are common to psoriasis and other complex disorders; these include HLA-Cw6 and TNF-alpha. Furthermore, interleukin-6 (IL-6), IL-8, interferon-gamma, IL-1, and IL-17 are also implicated in the generation of proatheromatous abnormalities like dyslipidemia, insulin resistance, endothelial dysfunction, clotting system activation, and prooxidative stress. ${ }^{1}$ TNFalpha is a potent activator of c-Jun amino-terminal kinase, which stimulates the main regulator of proinflammatory activity protein-1 and is connected with obesity. It can also lead to insulin resistance by inhibiting the phosphorylation of insulin receptor tyrosine and of insulin receptor substrate 1. Treatment with TNF-inhibitors affects the increase of HDL levels, reducing total HDL levels; specifically, TNF-alpha may affect endothelium dysfunction by decreasing the levels of nitric oxide synthase and cyclooxygenase-1.,

Lipoprotein metabolism is richly influenced by genetic variation, and the expression of dyslipidemias in response to obesity and/or insulin resistance varies from patient to patient. Psoriasis has been associated with abnormal metabolism of plasma lipids, and diabetes is possibly related to alterations in insulin secretion and sensitivity. ${ }^{9}$ Changes in lipid metabolism among psoriasis patients may be related to several abnormalities of the digestive system. The digestive system takes an active part in the process of lipid metabolism. Structural and functional abnormalities have been found in nearly all segments of the digestive system. ${ }^{10}$

Other comorbid factors that increase the risk of abnormal lipid metabolism may be found in these patients.
These include a higher body mass index $\left(>30 \mathrm{~kg} / \mathrm{m}^{2}\right)$, a family history of hyperlipidemia, a sedentary life style, a high fat diet, and a patient taking retinoids or cyclosporine to treat the disease. ${ }^{11,12}$ Antipsoriatic drugs can be also responsible for lipid profile disturbances in psoriatic patients because of their action on the circulating lipids. Recently it has been shown that infliximab, which is used to treat patients with psoriatic arthritis, can also increase triglyceride levels in psoriatic patients. ${ }^{13}$

Hyperlipidemia can be treated with statins, which effectively reduce C-reactive protein and TNF levels, as well as decrease levels of LDLs and alleviate arterial stiffness. Statins also downregulate adhesion molecules such as LFA-1 and ICAM-1 on leukocytes and endothelial cells, which are essential in leukocyte activation, leukocyte migration to inflammatory sites, and immunologic cytotoxicity. ${ }^{14}$

Mallbris et $\mathrm{al}^{2}$ investigated whether individuals with newly diagnosed psoriasis have abnormal lipid profiles when compared to age and gender-matched controls. They observed higher total cholesterol and serum LDL levels, and lower HDL levels in the cases corresponding to the control group, but the difference was statistically significant only for HDL levels (ie, $P$-value $<0.05)$. In a study conducted by Piskin, ${ }^{5}$ it was found that serum total and LDL cholesterol levels were significantly higher than those of controls. ${ }^{5}$ Therefore, uniformity of the results is not apparent in various studies.

A number of conflicting findings have been reported about the various parameters and lipid profiles studied among psoriatic patients, with some studies reporting high levels, and some reporting normal levels across a number of the same measures. In our study, even though levels were high for total cholesterol and LDL levels among psoriatic patients, the differences were not statistically significant when compared to controls; however, the correlations between the various parameters among cases and controls showed highly significant differences. The limitations of our study include the small sample size used, and the fact that the differences noted in plasma levels between participants and controls were not statistically significant.

This study has illustrated that the elevated levels of total cholesterol, LDL cholesterol, and triglycerides, as well as the lowering of HDL levels is evident in the general population, which ultimately indicates that people are becoming increasingly susceptible to various cardiovascular and metabolic diseases.

\section{Disclosure}

The authors report no conflicts of interest in this work. 


\section{References}

1. Pietrzak A, Michalak-Stoma A, Chodorowska G, Szepietowski JC. Lipid disturbances in psoriasis: an update. Mediators Inflamm. 2010;2010. pii: 535612.

2. Mallbris L, Granath F, Hamsten A, Ståhle M. Psoriasis is associated with lipid abnormalities at the onset of skin disease. J Am Acad Dermatol. 2006;54(4):614-621.

3. Akhyani M, Ehsani AH, Robati RM, Robati AM. The lipid profile in psoriasis: a controlled study. J Eur Acad Dermatol Venereol. 2007;21(10):1330-1332.

4. Pietrzak A, Lecewicz-Torun B. Activity of serum lipase [EC 3.1.1.3] and the diversity of serum lipid profile in psoriasis. Med Sci Monit. 2002;8(1):CR9-CR13.

5. Piskin S, Gurkok F, Ekuklu G, Senol M. Serum lipid levels in psoriasis. Yonsei Med J. 2003;44(1):24-26.

6. Javidi Z, Meibodi NT, Nahidi Y. Serum lipids abnormalities and psoriasis. Indian J Dermatol. 2007;52(2):89-92.

7. Lea WA Jr, Cornish HH, Block WD. Studies on serum lipids, proteins, and lipoproteins in psoriasis. J Invest Dermatol. 1958;30(4):181-185.

8. Karadag AS, Yavuz B, Ertugrul DT, et al. Is psoriasis a pre-atherosclerotic disease? Increased insulin resistance and impaired endothelial function in patients with psoriasis. Int J Dermatol. 2010;48(6):642-646.
9. Ucak S, Ekmekci TR, Basat O, Koslu A, Altuntas Y. Comparison of various insulin sensitivity indices in psoriatic patients and their relationship with type of psoriasis. $J$ Eur Acad Dermatol Venereol. 2006;20(5):517-522.

10. Pietrzak A, Lecewicz-Torun B, Kadziela-Wypyska G. Changes in the digestive system in patients suffering from psoriasis. Ann Univ Mariae Curie Sklodowska Med. 1998;53:187-194.

11. Edwards BD, Bhatnagar D, Mackness MI, et al. Effect of low-dose cyclosporin on plasma lipoproteins and markers of cholestasis in patients with psoriasis. QJM. 1995;88(2):109-113.

12. Seçkin D, Tokgözoğlu L, Akkaya S. Are lipoprotein profile and lipoprotein (a) levels altered in men with psoriasis? $J$ Am Acad Dermatol. 1994;31(3 Pt 1):445-449.

13. Castro KR, Aikawa NE, Saad CG, et al. Infliximab induces increase in triglyceride levels in psoriatic arthritis patients. Clin Dev Immunol. 2011;2011:352686.

14. Rajpara AN, Goldner R, Gaspari A. Psoriasis: can statins play a dual role? Dermatol Online J. 2010;16(2):2.
Psoriasis: Targets and Therapy

\section{Publish your work in this journal}

Psoriasis: Targets and Therapy is international, peer-reviewed, open access journal focusing on psoriasis, nail psoriasis, psoriatic arthritis and related conditions, identification of therapeutic targets and the optimal use of integrated treatment interventions to achieve improved outcomes and quality of life. The manuscript management system

\section{Dovepress}

is completely online and includes a very quick and fair peer-review system. Visit http://www.dovepress.com/testimonials.php to read real quotes from published authors. 